\title{
Adubação mineral e orgânica no desenvolvimento de crisântemo
}

\section{Mineral fertilization and organic fertilization on chrysanthemun growth}

\author{
Ana Maria Conte e Castro ${ }^{*}$; Osvaldo Sato ${ }^{1}$; Kleber Henrique dos Santos ${ }^{2}$; \\ Rafael Aguiar Zaparolli²; Sérgio Birello Sartori²; Gilberto Bueno Demétrio ${ }^{3}$
}

\section{Resumo}

O objetivo do trabalho foi avaliar a utilização de produtos orgânicos em comparação com adubação mineral no desenvolvimento do crisântemo. O delineamento experimental foi blocos ao acaso, composto por 7 tratamentos, 9 repetições: T1 (100\% de substrato comercial-SC+ adubação mineral-AM1); T2 (100\% SC + AM2); T3 (100\% SC + AM3); T4 (100\% SC + AM4); T5 (70\% SC + 30\% esterco bovino); T6 (70\% SC $+30 \%$ de esterco de ovinos); $\mathrm{T} 7$ ( $70 \% \mathrm{SC}+30 \%$ esterco de aves). A adubação mineral foi realizada na forma de fertirrigação com $\mathrm{AM} 1=$ (nitrato de cálcio $0,2 \mathrm{~g} \mathrm{~L}^{-1}$, sulfato de amônio $0,4 \mathrm{~g} \mathrm{~L}^{-1}$, nitrato de potássio $0,2 \mathrm{~g} \mathrm{~L}^{-1}$, sulfato de magnésio $0,3 \mathrm{~g} \mathrm{~L}^{-1}$ e mono amônio fosfato $\left.0,05 \mathrm{~g} \mathrm{~L}^{-1}\right)$, na dose de 50 $\mathrm{ml}$ por vaso; $\mathrm{AM} 2=\mathrm{ULTRAFLOR}^{\circledR}\left(12 \% \mathrm{~N}, 6 \% \mathrm{P}_{2} \mathrm{O}_{5}, 12 \% \mathrm{~K}_{2} \mathrm{O}\right)$, aplicando $0,8 \mathrm{~g} \mathrm{vaso}^{-1}$, mensalmente; AM3 $=$ NUTRIVERDE $^{\circledR}\left(13 \% \mathrm{~N}, 13 \% \mathrm{P}_{2} \mathrm{O}_{5}, 15 \% \mathrm{~K}_{2} \mathrm{O}, 1 \% \mathrm{Ca}, 4 \% \mathrm{~S}, 1 \% \mathrm{Mg}, 0,05 \% \mathrm{~B}, 0,005 \% \mathrm{Co}\right.$, $0,05 \% \mathrm{Cu}, 0,2 \% \mathrm{Fe}, 0,005 \% \mathrm{Mo}, 0,1 \% \mathrm{Zn}$ ), aplicando $2,6 \mathrm{~g} \mathrm{~L}^{-1}, 100 \mathrm{~mL}^{-1}$ vaso $^{-1}$, quinzenalmente $\mathrm{e}$ AM4 $=$ OURO VERDE ${ }^{\circledR}\left(15 \% \mathrm{~N}, 15 \% \mathrm{P}_{2} \mathrm{O}_{5}, 20 \% \mathrm{~K}_{2} \mathrm{O}\right)$, aplicando $2,0 \mathrm{~g} \mathrm{vaso}^{-1}$, quinzenalmente. Foram amostrados o número de hastes secundárias, altura de planta, diâmetro da haste e das inflorescências, número de folhas e de inflorescências e peso da massa verde da parte aérea. Recomenda-se a adubação mineral formulada (T1) ou a adubação com esterco bovino ou de aves. Dentre os produtos comercias, o nutriverde ${ }^{\circledR}$ pode ser utilizado.

Palavras chave: Adubo orgânico, substrato. Dendranthema grandiflora

\begin{abstract}
The objective was to evaluated organic products in comparison with mineral fertilization in the growth of chrysanthemum crop. The experimental design was randomized blocks with seven treatments and nine replications. The treatments were $\mathrm{T} 1(100 \%$ of commercial substratum $-\mathrm{CS}+$ mineral fertilization - AM1); T2 (100\% of CS + AM2); T3 (100\% of CS + AM3); T4 (100\% of CS + AM4); T5 (70\% of $\mathrm{CS}+30 \%$ bovine manure); T6 (70\% of CS $+30 \%$ of sheep manure); T7 (70\% of CS $+30 \%$ poultry manure). The mineral fertilization was carried through fertigation with $\mathrm{AM} 1=$ (calcium nitrate $0,2 \mathrm{~g}$ $\mathrm{L}^{-1}$, ammonium sulphate $0,4 \mathrm{~g} \mathrm{~L}^{-1}$, potassium nitrate $0,2 \mathrm{~g} \mathrm{~L}^{-1}$, magnesium sulphate $0,3 \mathrm{~g} \mathrm{~L}^{-1}$ and mono ammonium 0,05 phosphate $\left.\mathrm{g} \mathrm{L}^{-1}\right)$, in the dosage of $50 \mathrm{ml}$ for pot, AM2 = ULTRAFLOR ${ }^{\circ}(12 \% \mathrm{~N}$, $6 \% \mathrm{P} 2 \mathrm{O} 5,12 \% \mathrm{~K} 2 \mathrm{O}$ ), applying $0,8 \mathrm{~g}^{-1}$ pot $^{-1}$, monthly, AM3 $=$ Nutriverde ${ }^{\circledR}=13 \% \mathrm{~N}, 13 \% \mathrm{P} 2 \mathrm{O} 5,15 \%$ K2O, $1 \%$ Here, $4 \% \mathrm{~S}, 1 \% \mathrm{Mg}, 0.05 \% \mathrm{~B}, 0.005 \% \mathrm{Co}, 0.05 \% \mathrm{Cu}, 0.2 \%$ Faith, $0.005 \% \mathrm{Me}, 0.1 \% \mathrm{Zn}$, applying 2,6 g L-1 $\left(100 \mathrm{~m} \mathrm{~L} \mathrm{pot}^{-1}\right)$, fortnightly and AM4 $=$ Ouro Verde ${ }^{\circledR}=15 \% \mathrm{~N}, 15 \% \mathrm{P} 2 \mathrm{O} 5,20 \%$ $\mathrm{K} 2 \mathrm{O}$, applying $2,0 \mathrm{~g} \mathrm{pot}^{-1}$, fortnightly. It was evaluated the number of secondary stems, plant height,
\end{abstract}

\footnotetext{
1 Docentes da Universidade Estadual do Norte do Paraná - Campus Luiz Meneghel - Bandeirantes . Departamento de Produção Vegetal. Bandeirantes /PR.. E-mail: acastro@ffalm.br, oksato@ffalm.br

2 Acadêmicos do Curso de Agronomia Universidade Estadual do Norte do Paraná - Campus Luiz Meneghel- Bandeirantes. E-mail: kleber_hs@hotmail.com, zapparoli@ffalm.br, sergio-sartori@hotmail.com

3 Biólogo, Mestre. Laboratório de Fertilidade de Solo da Universidade Estadual do Norte do Paraná - Campus Luiz MeneghelBandeirantes. E-mail: labsolos@ffalm.br

* Autor para correspondência
} 
stem diameter and the inflorescences diameter, leaf number and inflorescences number and aerial fresh mass weight. The formulated mineral fertilization (T1) or manure of bovine (T5) or poultry (T7) is recommended. Among the commercial products the Nutriverde ${ }^{\circledR}$ is suggested to be used.

Key words: Organic fertilizer, substratum, Dendranthema grandiflora

\section{Introdução}

Entre as diferentes atividades agrícolas destacase a produção de flores, já que o Brasil está entre os grandes produtores, com um volume orçamentário na ordem de 2 bilhões de dólares no ano de 2007 e com exportações chegando a 37 milhões de dólares, atingindo uma balança comercial positiva (IBRAFLOR 2007).

A cultura do crisântemo é, em volume de comercialização, a mais comercializada no Brasil se forem consideradas as duas formas de produção, ou seja, flor de corte e de vaso. Seu pico de comercialização é no feriado de finados, vendida como flor de vaso (BARBOSA et al., 2005).

O cultivo de crisântemo se destaca pela facilidade de cultivo, resposta fotoperiódica, grande variedade de formas, cores e durabilidade, sendo comercializado o ano todo (LOPES, 2003).

O cultivo de flores no Brasil é realizado com emprego de altas tecnologias e a adubação mineral se destaca em detrimento ao uso de materiais orgânicos, já que o ciclo da maioria das culturas envasadas é curto e os adubos químicos geralmente são prontamente disponíveis para as culturas.

Atualmente são utilizados materiais alternativos, geralmente resíduos, como adubação orgânica para as flores, como componentes de substratos, em complementação à adubação química e como condicionadores de solos (CONTE E CASTRO et al., 2001; RUPPENTHAL; CONTE E CASTRO, 2005; CONTE E CASTRO et al., 2006).

Esses materiais podem ser utilizados diretamente no solo ou através de compostagem, resultando num produto estabilizado com larga utilidade para a agricultura e com vantagens na melhoria das propriedades físicas e químicas do solo, sendo usados também como substratos para produção de mudas e em plantas envasadas (OLIVEIRA, 1997).

Simões e Castilho (2000), analisando o desenvolvimento da gérbera, constataram que o melhor desenvolvimento das plantas ocorreu em substrato mais terra mais esterco de curral com porcentagem de florescimento $33 \%$ superior à utilização de adubação química.

Quantos às características físicas, Conte e Castro et al. (2008) observaram melhor estruturação, densidade e porosidade, quando utilizaram $10 \mathrm{t} \mathrm{ha}^{-1}$ de cama de aviário, se comparada a outros resíduos e em diferentes doses em comparação a adubação mineral.

Trabalhando com duas variedades de crisântemo de vaso, em diferentes misturas de substratos contendo compostos orgânicos, Stringheta et al. (2003) concluíram que, excetuando o K, os demais nutrientes avaliados foram influenciados pelas maiores concentrações de compostos orgânicos utilizados.

Ruppenthal e Conte e Castro (2005), trabalhando com a cultura do gladíolo, utilizando como adubo orgânico o composto de lixo urbano, observaram que a dose de $10 \mathrm{t} \mathrm{ha}^{-1}$ proporcionou condições suficientes para adequada nutrição, desenvolvimento e produção.

Utilizandocompostodelixourbanonacomposição de substrato para produção de crisântemo, CONTE E CASTRO et al. (2006) observaram que, em mistura com outros produtos orgânicos, o composto proporcionou maior desenvolvimento das plantas e foi economicamente viável.

Este trabalho teve como objetivo avaliar a utilização de adubos orgânicos em comparação com diferentes adubos comerciais como fonte mineral no desenvolvimento do crisântemo. 


\section{Materiais e métodos}

O experimento foi conduzido em vaso, sob cultivo protegido, utilizando a variedade de crisântemo Pink Mega Time. Foram utilizados sete tratamentos com nove repetições, num total de 63 vasos, em delineamento experimental de blocos ao acaso. Os tratamentos foram T1 (100\% de substrato comercial - Plantmax ${ }^{\circledR}+$ adubação mineral do produtor-AM1); T2 (100\% de substrato comercial + AM2); T3 (100\% de substrato comercial + AM3); T4 (100\% de substrato comercial + AM4); T5 (70\% de substrato comercial $+.30 \%$ esterco bovino); T6 (70\% de substrato comercial $+30 \%$ de esterco de ovinos); T7 (70\% de substrato comercial $+30 \%$ esterco de aves), sendo que AM1 = (nitrato de cálcio $0,2 \mathrm{~g} \mathrm{~L}^{-1}$, sulfato de amônio $0,4 \mathrm{~g} \mathrm{~L}^{-1}$, nitrato de potássio $0,2 \mathrm{~g} \mathrm{~L}^{-1}$, sulfato de magnésio $0,3 \mathrm{~g} \mathrm{~L}^{-1} \mathrm{e}$ mono amônio fosfato $0,05 \mathrm{~g} \mathrm{~L}^{-1}$ ), na dose de $50 \mathrm{ml}$ da solução por vaso, AM2 $=$ Ultraflor $^{\circledR}$ aplicando $0,8 \mathrm{~g}$ vaso $^{-1}$, mensalmente, AM3 $=$ Nutriverde $^{\circledR}$, aplicando $2,6 \mathrm{~g} \mathrm{~L}^{-1}\left(100 \mathrm{~mL}_{\text {vaso }}{ }^{-1}\right)$, quinzenalmente e AM4 = Ouro Verde ${ }^{\circledR}$ aplicando 2,0g vaso ${ }^{-1}$, quinzenalmente. $\mathrm{Na}$ adubação mineral formulada foram realizadas semanalmente, através de fertirrigação, duas soluções: 1) nitrato de cálcio $0,2 \mathrm{~g} \mathrm{~L}^{-1}$ e sulfato de amônio $0,4 \mathrm{~g} \mathrm{~L}^{-1}$; 2) nitrato de potássio $0,2 \mathrm{~g} \mathrm{~L}^{-1}$, sulfato de magnésio $0,3 \mathrm{~g} \mathrm{~L}^{-1}$ e mono amônio fosfato $0,05 \mathrm{~g} \mathrm{~L}^{-1}$.

As concentrações e composição dos diferentes adubos minerais utilizados são apresentados na (Tabela 1), e a composição química dos adubos orgânicos é apresentada na (Tabela 2).

Tabela 1. Composição dos adubos comerciais utilizados no experimento.

\begin{tabular}{|c|c|c|}
\hline Adubo comercial & Doses & Composição \\
\hline $\begin{array}{l}\text { AM1= } \\
\text { formubação mineral } \\
\text { forma }\end{array}$ & 50 ml.vaso ${ }^{-1}$ & $\begin{array}{l}\text { nitrato de cálcio } 0,2 \mathrm{~g} \mathrm{~L}^{-1} \text {, sulfato de amônio } 0,4 \mathrm{~g} \mathrm{~L}^{-1} \text {, nitrato de } \\
\text { potássio } 0,2 \mathrm{~g} \mathrm{~L}^{-1} \text {, sulfato de magnésio } 0,3 \mathrm{~g} \mathrm{~L}^{-1} \mathrm{e} \text { mono amônio } \\
\text { fosfato } 0,05 \mathrm{~g} \mathrm{~L}^{-}\end{array}$ \\
\hline $\mathrm{AM} 2=$ Ultraflor $^{\circledR}$ & $0,8 \mathrm{~g} \cdot$ vaso $^{-1}$ & $12 \% \mathrm{~N} ; 6 \% \mathrm{P}_{2} \mathrm{O}_{5} ; 12 \% \mathrm{~K}_{2} \mathrm{O}$ \\
\hline AM3 $=$ Nutriverde $^{\circledR}$ & $2,6 \mathrm{~g} \cdot \mathrm{L}^{-1}$ & $\begin{array}{c}13 \% \mathrm{~N} ; 13 \% \mathrm{P}_{2} \mathrm{O}_{5} ; 15 \% \mathrm{~K}_{2} \mathrm{O} ; 1 \% \mathrm{Ca} ; 4 \% \mathrm{~S} ; 1 \% \mathrm{Mg} ; 0,05 \% \mathrm{~B} \\
0,005 \% \mathrm{Co} ; 0,05 \% \mathrm{Cu} ; 0,2 \% \mathrm{Fe} ; 0,005 \% \mathrm{Mo} ; 0,1 \% \mathrm{Zn}\end{array}$ \\
\hline AM4= Ouro Verde ${ }^{\circledR}$ & 2,0 g.vaso ${ }^{-1}$ & $15 \% \mathrm{~N} ; 15 \% \mathrm{P}_{2} \mathrm{O}_{5} ; 20 \% \mathrm{~K}_{2} \mathrm{O}$ \\
\hline
\end{tabular}

Tabela 2. Resultado da análise química do esterco bovino, aves e ovino.

\begin{tabular}{|c|c|c|c|c|c|c|c|c|c|}
\hline \multirow{2}{*}{ Produto orgânico } & $\mathrm{N}$ & $\mathrm{P}$ & $\mathrm{K}$ & $\mathrm{Ca}$ & $\mathrm{Mg}$ & $\mathrm{Cu}$ & $\mathrm{Zn}$ & $\mathrm{Mn}$ & \multirow[t]{2}{*}{$\mathrm{Fe}$} \\
\hline & 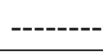 & \multicolumn{4}{|c|}{$\mathrm{g} \mathrm{kg}^{-1}---------$} & & $----m$ & 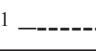 & \\
\hline Esterco bovino & 12,2 & 3,70 & 1,70 & 7,20 & 2,10 & 160 & 61 & 235 & 1100 \\
\hline Esterco de aves & 16,5 & 3,99 & 2,30 & 9,30 & 3,40 & 162 & 125 & 1547 & 265 \\
\hline Esterco ovino & 11,6 & 1,70 & 1,20 & 9,20 & 3,20 & 164 & 122 & 435 & 185 \\
\hline
\end{tabular}

A cultura foi conduzida com o plantio de seis estacas pré-enraizadas em vasos $\mathrm{n}^{-} 15$, com capacidade de $1,3 \mathrm{~L}$, num total de 378 plantas. $\mathrm{O}$ crisântemo foi cultivada entre maio e agosto de 2008. Como é considerada uma planta de dia curto, para indução ao florescimento, a cultura foi conduzida sob regime de luz, em que aproximadamente 15 dias foi fornecida iluminação artificial das 17:30 às 23:30 horas, até o desponte. Essa iluminação foi realizada com lâmpadas incandescentes de $100 \mathrm{~W}$, instaladas a $1,8 \mathrm{~m}$ de altura da planta. Após esse período, a cultura foi conduzida sem iluminação artificial e as plantas continuaram seu desenvolvimento. 
Como na fase reprodutiva, a planta necessita de 13 horas de escuro, o que ocorre naturalmente nesse período, não sendo necessário o escurecimento artificial para induzi-la ao florescimento.

As avaliações foram realizadas na colheita, obtendo-se os seguintes dados: número de hastes secundárias, altura de planta, número de folhas, diâmetro de haste, número de botões florais e diâmetro de inflorescência.
Os dados foram submetidos à análise de variância, utilizando-se o teste de Tukey a 5\% de probabilidade.

\section{Resultados e discussão}

Na Tabela 3, são apresentados o número de hastes secundárias e de folhas, altura de planta, diâmetro da haste e peso da massa verde da parte aérea em crisântemo de vaso submetida a adubações minerais e orgânicas.

Tabela 3. Características vegetativas do crisântemo 'Pink Mega Time', sob diferentes tratamentos de adubação.

\begin{tabular}{|c|c|c|c|c|c|}
\hline \multirow[b]{2}{*}{ Tratamentos } & \multicolumn{2}{|c|}{ Número } & \multirow{2}{*}{$\begin{array}{l}\text { Altura de planta } \\
\text { (cm) }\end{array}$} & \multirow{2}{*}{$\begin{array}{c}\text { Diâmetro de } \\
\text { haste }(\mathrm{cm})\end{array}$} & \multirow{2}{*}{$\begin{array}{c}\text { Biomassa fresca } \\
\text { (g) }\end{array}$} \\
\hline & $\begin{array}{c}\text { Hastes } \\
\text { secundárias }\end{array}$ & Folhas & & & \\
\hline $\begin{array}{c}\mathrm{T} 1=100 \% \\
\mathrm{SC}+\text { Adubação } \\
\text { mineral formulada } \\
\text { (testemunha) }\end{array}$ & $4,55 \mathrm{bc}$ & $82,67 \mathrm{a}$ & $27,81 \mathrm{a}$ & $0,43 \mathrm{ab}$ & $31,21 \mathrm{a}$ \\
\hline $\begin{array}{c}\mathrm{T} 2=100 \% \mathrm{SC}+ \\
\text { Ultraflor }^{\circledR}\end{array}$ & $3,77 \mathrm{c}$ & $64,57 b$ & $24,66 \mathrm{abc}$ & $0,42 \mathrm{ab}$ & $25,02 \mathrm{~cd}$ \\
\hline $\begin{array}{c}\mathrm{T} 3=100 \% \mathrm{SC}+ \\
\text { Nutriverde }^{\circledR}\end{array}$ & $4,05 \mathrm{bc}$ & $81,62 \mathrm{ab}$ & $26,84 a b$ & $0,44 \mathrm{ab}$ & $29,06 \mathrm{abc}$ \\
\hline $\begin{array}{c}\mathrm{T} 4=100 \% \mathrm{SC}+\text { Ouro } \\
\text { Verde }^{\circledR}\end{array}$ & $4,83 \mathrm{ab}$ & $76,05 \mathrm{ab}$ & $23,61 \mathrm{abc}$ & $0,43 \mathrm{ab}$ & $26,33 \mathrm{bcd}$ \\
\hline $\begin{array}{c}\mathrm{T} 5=70 \% \mathrm{SC}+30 \% \\
\text { esterco bovino }\end{array}$ & $4,83 \mathrm{ab}$ & $81,90 \mathrm{ab}$ & $26,33 \mathrm{ab}$ & $0,45 \mathrm{a}$ & $24,76 \mathrm{~d}$ \\
\hline $\begin{array}{c}\mathrm{T} 6=70 \% \mathrm{SC}+30 \% \\
\quad \text { esterco ovino }\end{array}$ & $3,83 \mathrm{c}$ & $64,50 \mathrm{~b}$ & $21,35 \mathrm{c}$ & $0,39 b$ & $18,82 \mathrm{e}$ \\
\hline $\begin{array}{c}\mathrm{T} 7=70 \% \mathrm{SC}+30 \% \\
\text { esterco aves }\end{array}$ & $5,61 \mathrm{a}$ & $80,22 \mathrm{ab}$ & $22,09 b \mathrm{c}$ & $0,44 \mathrm{a}$ & $29,87 \mathrm{ab}$ \\
\hline F & $* *$ & $*$ & $* *$ & $*$ & $* *$ \\
\hline DMS & 0,99 & 17,14 & 4,76 & 0,04 & 4,06 \\
\hline CV (\%) & 7,77 & 7,62 & 6,75 & 3,33 & 5,37 \\
\hline
\end{tabular}

$\mathrm{SC}=$ substrato comercial Plantmax ${ }^{\circledR}$

$* * \mathrm{e}^{*}=$ significativo a $1 \%$ e $5 \%$ do teste $\mathrm{F}$. Ns = não significativo. Letras iguais minúsculas na coluna não diferem pelo Teste de Tukey a $5 \%$ de probabilidade. 
Para a comercialização de crisântemo o número de hastes secundárias obtidas após o desponte, é uma importante característica, pois ela está associada ao número de botões florais e inflorescências na época de colheita. Assim na Tabela 3 se observa que quando se utilizou esterco de bovino e de aves houve um maior número de hastes secundárias por vaso, e que a adubação mineral formulada (testemunha) foi estatisticamente semelhante às adubações minerais com os produtos Ouro Verde ${ }^{\circledR}$ e Nutriverde ${ }^{\circledR}$. O menor número de hastes foi encontrado quando se utilizou o esterco ovino e o Ultraflor ${ }^{\circledR}$, provavelmente em razão do menor valor nutricional desses produtos (Tabelas 1 e 2).

$\mathrm{O}$ número de folhas também seguiu o comportamento estatístico do número de hastes, ou seja, o uso de adubo ultraflor ${ }^{\circledR}$ e do esterco ovino induziu menor número de folhas.

A altura de plantas, apesar de apresentar diferenças estatísticas entre os tratamentos, está dentro do padrão adequado de comercialização para todos os tratamentos, pois a altura das plantas deve ser menor que duas vezes a altura do vaso e o vaso utilizado no experimento tinha $15 \mathrm{~cm}$ de altura (GRUSZYNSKI, 2001). Resultados semelhantes foram obtidos por Stringheta et al. (1996), na cultura do crisântemo e Ruppenthal e Conte e Castro (2005), para o gladíolo.

O diâmetro da haste é também um importante parâmetro a ser avaliado, pois hastes delgadas podem não suportar o peso das inflorescências.
O uso de esterco bovino e de aves foram os que determinaram hastes mais espessas, embora estatisticamente, só diferiram do uso de esterco ovino. Os diâmetros foram em média $4,2 \mathrm{~mm}$, inferiores aos valores encontrados por Gruszynski (2001). Porém, esse autor cita que diâmetro acima de $6 \mathrm{~mm}$ são consideradas ideais para o cultivo do crisântemo, utilizados para corte, enquanto que no presente trabalho as plantas eram de vaso.

A biomassa fresca da parte aérea é conseqüência da somatória das hastes + folhas + inflorescências. Pode-se notar na (Tabela 3) que a adubação mineral formulada (testemunha), o uso do adubo nutriverde ${ }^{\circledR}$ e a mistura de esterco de aves ao substrato resultaram em maior massa de plantas por vaso, sugerindo plantas com arquitetura visualmente melhor, para comercialização. O nutriverde ${ }^{\circledR}$ é entre os produtos comerciais utilizados no experimento o único rico em micronutrientes (Tabela 1), essencial ao desenvolvimento das plantas.

O número de botões florais e de inflorescências e o diâmetro das inflorescências estão apresentados na (Tabela 4), onde se pode observar que o número de botões florais não variou estatisticamente com as diferentes adubações utilizadas, porém o número de inflorescências totalmente abertas na época de comercialização, bem como seu tamanho, tiveram uma variação estatisticamente significativa. Com exceção do uso de esterco ovino, os demais tratamentos produziram maior número de inflorescências abertas, característica importante, pois significa um vaso mais compacto. 
Tabela 4. Número de botões florais e de inflorescências e diâmetro da inflorescência de crisântemo 'Pink Mega Time' sob diferentes tratamentos de adubação.

\begin{tabular}{cccc}
\hline \multirow{2}{*}{ Tratamentos } & \multicolumn{2}{c}{ Número } & Diâmetro da \\
\cline { 2 - 3 } & Botões florais & Inflorescência & inflorescência (cm) \\
\hline $\mathrm{T} 1=100 \% \mathrm{SC}+$ Adubação mineral formulada & 5,61 & $14,33 \mathrm{ab}$ & $7,38 \mathrm{a}$ \\
$\mathrm{T} 2=100 \% \mathrm{SC}+$ ultraflor $^{\circledR}$ & 5,71 & $14,83 \mathrm{ab}$ & $4,38 \mathrm{~b}$ \\
$\mathrm{~T} 3=100 \% \mathrm{SC}+$ nutriverde $^{\circledR}$ & 5,71 & $14,38 \mathrm{ab}$ & $5,33 \mathrm{ab}$ \\
$\mathrm{T} 4=100 \% \mathrm{SC}+$ ouro verde $^{\circledR}$ & 5,66 & $12,83 \mathrm{ab}$ & $4,44 \mathrm{~b}$ \\
$\mathrm{~T} 5=70 \% \mathrm{SC}+30 \%$ esterco bovino & 6,01 & $11,77 \mathrm{ab}$ & $5,38 \mathrm{ab}$ \\
$\mathrm{T} 6=70 \% \mathrm{SC}+30 \%$ esterco ovino & 5,45 & $8,99 \mathrm{c}$ & $4,16 \mathrm{~b}$ \\
$\mathrm{~T} 7=70 \% \mathrm{SC}+30 \%$ esterco aves & 5,52 & $16,55 \mathrm{a}$ & $5,94 \mathrm{ab}$ \\
\hline $\mathrm{F}$ & $\mathrm{ns}$ & $* *$ & $* *$ \\
$\mathrm{DMS}$ & 1,10 & 3,08 & 2,32 \\
$\mathrm{CV}(\%)$ & 6,82 & 8,04 & 15,35 \\
\hline
\end{tabular}

$\mathrm{SC}=$ substrato comercial Plantmax ${ }^{\circledR}$

** e $*$ significativo a $1 \%$ e $5 \%$ do teste $\mathrm{F}$. Ns = não significativo. Letras iguais minúsculas na coluna não diferem pelo Teste de Tukey a $5 \%$ de probabilidade

\section{Conclusão}

Para a variedade de crisântemo Pink Mega Time cultivada em vaso, recomenda-se a adubação usualmente realizada pelos produtores (mineral formulada) ou utilizar esterco bovino ou de aves.

Dentre os adubos vendidos comercialmente para produção de flores, recomenda-se o produto Nutriverde ${ }^{\circledR}$.

\section{Agradecimentos}

A Cooperativa Holambra/SP e Fazenda Terra Viva/Empresa BallVanZanten Schoenmaker, município de Artur Nogueira/SP.

\section{Referências}

BARBOSA, J. C.; GROSSI, J. A. S.; BARBOSA, M. S.; BACKES, F., A., L.. Cultivo de crisântemo em vasos. Informe Agropecuário, Empresa de Pesquisa Agropecuária de Minas Gerais: Floricultura, v. 26, n. 227, p. 36-43, 2005.

CONTE E CASTRO, A. M.; SILVA, S. C.; SILVA, L. P. E.; VACARIN, R. N. D.; PAULETTI, D. R.; DARTORA, J. Manejo de resíduos orgânicos nas características físicas do solo cultivado com crisântemo. In: REUNIÃO BRASILEIRA DE MANEJO E CONSERVAÇÃO DO SOLO E DA ÁGUA, 17., 2008, Rio de Janeiro. Anais... Rio de Janeiro:SBCS, 2008. CD-ROM.

CONTE E CASTRO, A M.; BOARO, C. S. F.; RODRIGUES, J. D.; ERIG, C. Composto de lixo urbano e lodo de esgoto, na produção de crisântemo para flor de corte cultivado em Latossolo Vermelho-Amarelo. Revista de Horticultura Ornamental, Campinas, v. 12, n. 2, p. 97-102, 2006.

CONTE E CASTRO, A. M.; RUPPENTHAL, V.; ZIGIOTTO, D. C.; BIANCHINI, M. I. F.; BACKES, C. Adubação orgânica na produção de gladíolo. Revista Scientia Agraria Paranensis, Marechal Cândido Rondon, v. 1, n. 1, p. 33-41, 2001.

GRUSZYNSKI, C. Produção comercial do crisântemo: vaso, corte e jardim. Guaiba: Agropecuária, 2001, 166 p.

INSTITUTO BRASILEIRO DE FLORICULTURA IBRAFLOR. Exportações deflores e plantas ornamentais. 2007. Disponível em: <www. Ibraflor.com.br>. Acesso em: 12 abr. 2008.

LOPES, L. F.; COSTA, A. C. S.; OLIVEIRA, P. S.; GIL, L. G.; ROCHA, R. A.. A. Utilização agrícola de resíduo industrial de galvanoplastia como fonte de nutrientes para a cultura do crisântemo. In: CONGRESSO BRASILEIRO DE CIÊNCIA DO SOLO, 19., 2003, Ribeirão Preto. Anais... Ribeirão Preto: SBCS, 2003. CD ROM. 
OLIVEIRA, S. Gestão dos resíduos sólidos urbanos na microrregião serra de Botucatu - caracterização física dos resíduos sólidos domésticos na cidade de Botucatul SP. 1997. Dissertação (Mestrado em Agronomia) - Faculdade de Ciências Agronômicas, Campus de Botucatu, Universidade Estadual Paulista, Butucatu.

RUPPENTHAL,V.; CONTE E CASTRO, A. M. Efeito do composto de lixo urbano na nutrição e produção do gladíolo. Revista Brasileira de Ciência do Solo, Viçosa, v. 29, n. 1, p. 145-150, 2005.

SIMÕES, A. C.; CASTILHO, R. M. M. Desenvolvimento de gérbera (Gérbera jamesonii Bolus), em diferentes materiais orgânicos. In: ENCONTRO ANUAL DE
INICIAÇÃO CIENTÍFICA, 9., 2000, Ilha Solteira. Anais... Ilha Solteira: UNESP, FEIS, 2000. p. 187-188.

STRINGHETA, A. C. O.; FONTES, L. E. F.; LOPES, L. C.; CARDOSO, A. A. Crescimento de crisântemo em substrato contendo composto de lixo urbano e casca de casca de arroz carbonizada. Pesquisa Agropecuária Brasileira, Brasília, v. 31, n. 11, p. 11-18, 1996.

STRINGHETA, A. C. O.; MARTINEZ, H. P.; CARDOSO, A. A.; COSTA, C. A.Teores foliares de macronutrientes em crisântemo cultivados em substrato contendo composto de lixo urbano e casca de arroz carbonizada. Revista Brasileira de Floricultura e Plantas Ornamentais, Campinas, v. 9, n. 2. p. 191-197, 2003. 
